\title{
Association between Catechol-O-Methyltransferase Functional Polymorphism and Male Suicide Completers
}

\author{
Hisae Ono', Osamu Shirakawa*,', Hideyuki Nushida², Yasuhiro Ueno ${ }^{2}$ and Kiyoshi Maeda' \\ 'Division of Psychiatry and Neurology, Department of Environmental Health and Safety, Faculty of Medical Sciences, Kobe University Graduate \\ School of Medicine, Kobe, Japan; ${ }^{2}$ Division of Legal Medicine, Department of Environmental Health and Safety, Faculty of Medical Sciences, Kobe \\ University Graduate School of Medicine, Kobe, Japan
}

\begin{abstract}
Suicide has been suggested to involve catecholaminergic dysfunction and to be related to genetics. Catechol-O-methyltransferase (COMT) I58Val/Met polymorphism (GenBank Accession No. Z2649I) is a polymorphism of the gene encoding COMT, a major enzyme in catecholamine inactivation. The COMT I58Val/Met polymorphism affects COMT activity, that is, the alleles encoding Val and Met are associated with relatively high and relatively low COMT activity, respectively. In this study, we hypothesized that the COMT I58Val/Met polymorphism is associated with suicide. The study population consisted of 163 suicide completers ( 112 males and 5 I females). We found that the genotype distribution of the COMT I58Val/Met polymorphism was significantly different between male suicide completers and male controls $(p=0.036)$, while the frequency of the $\mathrm{Val} / \mathrm{Val}$ genotype, a highactivity COMT genotype, was significantly less in male suicide completers than in male controls (OR: 0.52; 95\% CL: 0.31-0.89; $p=0.016)$. However, this was not the case in females. Our results suggest that the $\mathrm{Val} / \mathrm{Val}$ genotype is a protective factor against suicide in males.

Neuropsychopharmacology (2004) 29, 1374-1377, advance online publication, 5 May 2004; doi: I 0. I 038/sj.npp. 1300470
\end{abstract}

Keywords: suicide; catecholaminergic dysfunction; COMT I58Val/Met polymorphism; association study; gender differences

\section{INTRODUCTION}

Suicide has been suggested to involve catecholaminergic dysfunction and to be related to genetics. Catecholaminergic dysfunction has been observed in suicide. For example, low concentrations of 3-methoxy-4-hydroxyphenylglycol, a metabolite of norepinephrine, and homovanillic acid, a metabolite of dopamine, were observed in the cerebrospinal fluid of suicide attempters (Lester, 1995; Roy et al, 1986; Jones et al, 1990), and high concentrations of norepinephrine and decreased $\alpha 2$-adrenergic binding were observed in the prefrontal cortex of suicide victims (Arango et al, 1993). Genetic factors in suicide have been observed in family, twin, and adoption studies, and were found to be independent of psychiatric disorders (Roy et al, 1997).

Catecholaminergic dysfunction in suicide appears to be related to gene polymorphisms in catecholaminergic

\footnotetext{
*Correspondence: Dr O Shirakawa, Division of Psychiatry and Neurology, Department of Environmental Health and Safety, Faculty of Medical Sciences, Kobe University Graduate School of Medicine, 7 5-I Kusunoki-cho, Chuo-Ku, Kobe, 650-00 I7, Japan, Tel: + 8I 78382 6065, Fax: +8I 78382 6079, E-mail: sirakawa@kobe-u.ac.jp

Received 25 August 2003; revised 17 February 2004; accepted 22 March 2004

Online publication: 3I March 2004 at http://www.acnp.org/citations/ Npp03310403388/default.pdf
}

systems. Catechol-O-methyltransferase (COMT) is a major enzyme in catecholamine inactivation. COMT has a polymorphism named COMT 158Val/Met polymorphism (GenBank Accession No. Z26491), in which Val at codon 158 is replaced with Met. The alleles encoding Val and Met are associated with relatively high and relatively low COMT activity, respectively. The Val/Val genotype leads to a level of enzymatic activity three to four times that generated by the Met/Met genotype, while the $\mathrm{Val} / \mathrm{Met}$ genotype leads to an intermediate activity (Lachman et al, 1996).

The COMT 158Val/Met polymorphism has been shown to be associated with suicide-related disorders. For example, the Met allele (low COMT activity) was associated with aggressive behaviors or violent suicide attempts in schizophrenic patients (Strous et al, 1997; Lachman et al, 1998; Kotler et al, 1999; Nolan et al, 2000). The Met allele was also associated with depressive disorders (Ohara et al, 1998), although other studies did not find such an association (Frisch et al, 1999; Kunugi et al, 1997b).

We hypothesized, therefore, that the COMT $158 \mathrm{Val} / \mathrm{Met}$ polymorphism is associated with suicide, independently of psychiatric disorders. To test this hypothesis, we conducted a study of the association between the COMT 158Val/Met polymorphism and suicide completers in a Japanese population. 
Table I Genotype and Allele Frequencies of COMT I58Val/Met Polymorphism in Suicide Completers and Controls

\begin{tabular}{|c|c|c|c|c|c|}
\hline & \multicolumn{3}{|c|}{ Genotype frequency } & \multicolumn{2}{|c|}{ Allele frequency } \\
\hline & Val/Val (\%) & Val/Met (\%) & Met/Met (\%) & Val (\%) & Met (\%) \\
\hline Controls $(n=169)$ & $90(53 \%)$ & $61(36 \%)$ & $18(1 \mid \%)$ & $24 \mid(7 \mid \%)$ & $97(29 \%)$ \\
\hline Female suicide completers $(n=5 \mathrm{I})$ & 25 (49\%) & $19(37 \%)$ & $7(14 \%)$ & $69(68 \%)$ & $33(32 \%)$ \\
\hline Female controls $(n=55)$ & $28(50 \%)$ & $19(35 \%)$ & $8(15 \%)$ & $75(68 \%)$ & $35(32 \%)$ \\
\hline
\end{tabular}

\section{METHODS}

\section{Subjects}

The study population consisted of 163 suicide completers (112 males: mean age $\pm S D, 48.68 \pm 16.9$ years; 51 females: $47.12 \pm 19.8$ years), who were autopsied at the Division of Legal Medicine, Kobe University Graduate School of Medicine. All subjects were ethnically Japanese. The methods of suicide were hanging (80), jumping from heights (49), drug overdose (8), drowning (8), several deep cuts (5), jumping in front of a vehicle (4), burning (3), gas poisoning (2), and other methods (4). Most (155) of the cases were classified as violent suicides according to the criteria proposed by Asberg et al (1976). Accurate information about the clinical backgrounds of the suicide completers could not be obtained under our ethical code for genetic studies.

Control subjects (159 males, 223 females) were recruited from the general population of Kobe city area, Japan. All were healthy and of Japanese descent and none manifested psychiatric problems in brief interviews by psychiatrists. To match the age and gender of the suicide subjects, 169 subjects (114 males: $45.33 \pm 15.5$ years; 55 females: $48.9 \pm 18.7$ years; all unrelated) were randomly selected from the above group. Informed consent was obtained from each control subject. This study was approved by the Ethical Committee for Genetic Studies of Kobe University Graduate School of Medicine.

\section{Genotyping}

Peripheral blood was drawn from suicide completers and controls, and leukocyte DNA was extracted for genotype determination. The genotypes of the COMT $158 \mathrm{Val} / \mathrm{Met}$ polymorphism were determined by the method of Daniels et al (1996).

\section{Statistical Analyses}

The genotype distribution and Hardy-Weinberg equilibrium were tested with the $\chi^{2}$ test for quality of fit. Comparisons of the genotype or allele frequencies between groups were performed with a $\chi^{2}$ test. The level of significance was set at $p=0.05$.

\section{RESULTS}

Table 1 shows the genotype and allele frequencies of the COMT $158 \mathrm{Val} / \mathrm{Met}$ polymorphism in suicide completers and control subjects. There is a strong trend towards deviation from Hardy-Weinberg equilibrium in the male completers $\left(\chi^{2}=3.6 ; \mathrm{df}=1, p=0.057\right)$, while the genotype distributions in male/female controls and female suicide completers are in Hardy-Weinberg equilibrium. The allele frequencies in the controls were similar to those previously established for a Japanese population (Kunugi et al, 1997a; Ohmori et al, 1998; Ohara et al, 1998).

When the results for both genders were combined, the genotype distribution tended to be different between suicide completers and controls, although the difference was not significant $\left(\chi^{2}=5.4 ; \quad \mathrm{df}=2, \quad p=0.068\right)$. The allele frequencies were not different between suicide completers and controls $\left(\chi^{2}=2.2 ; \mathrm{df}=1, p=0.14\right)$. Similar results were obtained when only the violent suicide completers (155 of 163 subjects) were considered (data not shown).

In males, the genotype distribution was significantly different between suicide completers and controls $\left(\chi^{2}=6.7\right.$; $\mathrm{df}=2, \quad p=0.036)$. The genotype distribution of male suicide completers is also significantly different from controls of both genders combined $\left(\chi^{2}=8.40 ; \mathrm{df}=2\right.$, $p=0.015$, statistically significant tests are those having $p$ values less than 0.017, alpha $=0.05 / 3$ ). The $\mathrm{Val} / \mathrm{Val}$ genotype appeared less frequently in male suicide completers than in male controls. The Odds ratio for the $\mathrm{Val} / \mathrm{Val}$ genotype $v s$ the other genotypes was 0.52 (95\% CL: $0.31-0.89 ; p=0.016)$ in male suicide completers. The $\mathrm{Val} /$ Met genotype appeared more frequently in male suicide completers than in male controls. The Odds ratio for the Val/Met genotype $v s$ the other genotypes was 1.98 (95\% CL: 1.16-3.37; $p=0.012$ ) in male suicide completers. In allele frequencies, the $\mathrm{Val}$ allele tended to appear less frequently in male suicide completers than in male controls $\left(\chi^{2}=3.08\right.$; $\mathrm{df}=1, p=0.080)$.

Among females, no significant differences were found between suicide completers and controls in either genotype distribution $\left(\chi^{2}=0.086 ; \mathrm{df}=2, p=0.96\right)$, or in allele frequencies $\left(\chi^{2}=0.007 ; \mathrm{df}=1, p=0.93\right)$. 


\section{DISCUSSION}

This is the first study to examine the association between the COMT 158Val/Met polymorphism and suicide completers. We found that the Val/Val genotype, a high-activity COMT genotype, appeared less frequently in male suicide completers than in male controls. Among males, the risk for suicide in the $\mathrm{Val} / \mathrm{Val}$ genotype carriers was only about half that in other genotype carriers (Odds ratio 0.52). However, this was not the case in females. Consequently, our results suggest that (1) the Val/Val genotype is a factor that protects against suicide, and (2) the COMT 158Val/Met polymorphism is associated with suicide, specifically in males.

Our finding that the Val/Val genotype is a factor that protects against suicide implies that the other genotypes including the Met allele, a low-activity COMT allele, increase suicide risk. This generally supports the results of previous reports that the Met allele is associated with suicide-related disorders (Ohara et al, 1998; Strous et al, 1997; Lachman et al, 1998; Kotler et al, 1999; Nolan et al, 2000). In our study, the Met allele tended to appear more common in suicide completers, although it did not reach statistical significance. The higher frequency of the Met allele was mainly due to the increased $\mathrm{Val} / \mathrm{Met}$ genotype rather than to an increased Met/Met genotype. Why the Met/Met genotype did not increase is not clear. One possibility is that the frequency of the Met/Met genotype in our Japanese subjects is so low that the sample size is insufficient to detect a difference of the Met/Met genotype frequencies between suicide completers and controls. The frequency of the Met allele in Japanese subjects (approximately 0.3) is lower than that in Caucasian subjects (approximately 0.5) (Palmatier et al, 1999). Furthermore, in another Japanese study, the Val/Met genotype appeared more frequently in schizophrenics than in the controls, while the frequency of the Met/Met genotype was not significantly different between the two groups (Ohmori et al, 1998).

Our finding that the COMT $158 \mathrm{Val} / \mathrm{Met}$ polymorphism is associated with suicide specifically in males implies that this polymorphism affects catecholaminergic systems differently in males and females. One possible explanation for the gender-specific association is that estrogen in females modulates neurotransmission and neuronal excitability of catecholaminergic systems (Balthazart et al, 1996). In previous studies, the COMT $158 \mathrm{Val} / \mathrm{Met}$ polymorphism has been gender-specifically associated with several neuropsychiatric disorders: obsessive-compulsive disorders (Karayiorgou et al, 1999), narcolepsy (Dauvilliers et al, 2001), and attention deficit hyperactivity disorder (Qian et al, 2003). Moreover, the Met allele has been associated with violent suicide attempts specifically in male schizophrenic patients (Nolan et al, 2000).

In our study, the genotype distribution in the male suicide completers tended to deviate from Hardy-Weinberg equilibrium. There is little possibility of genotyping error only in the male suicide completers because the genotype distributions in other groups (male/female controls and female suicide completers) are in Hardy-Weinberg equilibrium. There is also little possibility of false-positive results due to population stratification in our study because the
Japanese population is considered ethnically homogeneous due to its geographical and historical isolation (Katoh et al, 2002).

Our research contains some limitations. First, psychiatric diagnoses were not available in this study under our ethical code for genetic studies. We cannot completely exclude the possibility that the genotype differences are secondary to the different frequencies of psychiatric disorders and not directly related to risk for suicide. Second, we did not test several SNPs and haplotypes in the COMT gene. A haplotype analysis (Shifman et al, 2002) could have detected a smaller effect of the COMT $158 \mathrm{Val} /$ Met polymorphism on suicide completers. Third, the sample size of the subjects enrolled may be insufficient. Especially, in the comparison between female suicide completers and female controls, the power of the analysis was calculated to be 0.07 . Considering that the COMT $158 \mathrm{Val} /$ Met polymorphism might have a very small effect on female suicide completers, we cannot completely exclude the possibility that our failure to find an association between the COMT $158 \mathrm{Val} / \mathrm{Met}$ polymorphism and female suicide completers is due to a type II error. A more conclusive study with a substantially larger sample size may be required. Despite these limitations, our study provides new evidence regarding a protective factor for suicide.

In conclusion, we propose that the $\mathrm{Val} / \mathrm{Val}$ genotype of the COMT $158 \mathrm{Val} / \mathrm{Met}$ polymorphism, a high-activity COMT genotype, is a factor that protects against suicide specifically in males in the Japanese population.

\section{ACKNOWLEDGEMENTS}

This research was supported by a Research Grant for Nervous and Mental Disorders from the Ministry of Health, Labor and Welfare Japan, by Grants from the Ministry of Education, Science, Culture and Sports, and by Health Sciences Research Grants from the Ministry of Health, Labor and Welfare, Japan.

\section{REFERENCES}

Arango V, Ernsberger P, Sved AF, Mann JJ (1993). Quantitative autoradiography of alpha 1- and alpha 2-adrenergic receptors in the cerebral cortex of controls and suicide victims. Brain Res 30: 271-282.

Asberg M, Traskman L, Thoren P (1976). 5-HIAA in the cerebrospinal fluid. A biochemical suicide predictor? Arch Gen Psychiatry 33: 1193-1197.

Balthazart J, Foidart A, Absil P, Harada N (1996). Effects of testosterone and its metabolites on aromatase-immunoreactive cells in the quail brain: relationship with the activation of male reproductive behavior. J Steroid Biochem Mol Biol 48: 185-200.

Daniels JK, Williams NM, Williams J, Jones LA, Cardno AG, Murphy KC et al (1996). No evidence for allelic association between schizophrenia and a polymorphism determining high or low catechol-O-methyltransferase activity. Am J Psychiatry 153: $268-270$.

Dauvilliers Y, Neidhart E, Lecendreux M, Billiard M, Tafti M (2001). MAO-A and COMT polymorphisms and gene effects in narcolepsy. Mol Psychiatry 6: 367-372.

Frisch A, Postilnick D, Rockah R, Michaelovsky E, Postilnick S, Birman E et al (1999). Association of unipolar major depressive 
disorder with genes of the serotonergic and dopaminergic pathways. Mol Psychiatry 4: 389-392.

Jones JS, Stanley B, Mann JJ, Frances AJ, Guido JR, TraskmanBendz L et al (1990). CSF 5-HIAA and HVA concentrations in elderly depressed patients who attempted suicide. $A m \mathrm{~J}$ Psychiatry 147: 1225-1227.

Karayiorgou M, Sobin C, Blundell ML, Galke BL, Malinova L, Goldberg $\mathrm{P}$ et al (1999). Family-based association studies support a sexually dimorphic effect of COMT and MAOA on genetic susceptibility to obsessive-compulsive disorder. Biol Psychiatry 45: 1178-1189.

Katoh T, Mano S, Ikuta T, Munkhbat B, Tounai K, Ando $\mathrm{H}$ et al (2002). Genetic isolates in East Asia: a study of linkage disequilibrium in the $\mathrm{X}$ chromosome. Am J Hum Genet 71: 395-400.

Kotler M, Barak P, Cohen H, Averbuch IE, Grinshpoon A, Gritsenko I et al (1999). Homicidal behavior in schizophrenia associated with a genetic polymorphism determining low catechol-O-methyltransferase (COMT) activity. Am J Med Genet 88: 628-633.

Kunugi H, Nanko S, Ueki A, Otsuka E, Hattori M, Hoda F et al (1997a). High and low activity alleles of catechol$O$-methyltransferase gene: ethnic difference and possible association with Parkinson's disease. Neurosci Lett 221: 202-204.

Kunugi H, Vallada HP, Hoda F, Kirov G, Gill M, Aitchison KJ et al (1997b). No evidence for an association of affective disorders with high- or low-activity allele of catechol-O-methyltransferase gene. Biol Psychiatry 42: 282-285.

Lachman HM, Nolan KA, Mohr P, Saito T, Volavka J (1998). Association between catechol- $O$-methyltransferase genotype and violence in schizophrenia and schizoaffective disorder. $A m \mathrm{~J}$ Psychiatry 155: 835-837.

Lachman HM, Papolos DF, Saito T, Yu YM, Szumlanski CL, Weinshilboum RM (1996). Human catechol-O-methyltransferase pharmacogenetics: description of a functional polymorphism and its potential application to neuropsychiatric disorders. Pharmacogenetics 6: 243-250.
Lester D (1995). The concentration of neurotransmitter metabolites in the cerebrospinal fluid of suicidal individuals: a metaanalysis. Pharmacopsychiatry 28: 45-50.

Nolan KA, Volavka J, Czobor P, Cseh A, Lachman H, Saito T et al (2000). Suicidal behavior in patients with schizophrenia is related to COMT polymorphism. Psychiatr Genet 10: 117-124.

Ohara K, Nagai M, Suzuki Y, Ohara K (1998). Low activity allele of catechol-O-methyltransferase gene and Japanese unipolar depression. Neuroreport 9: 1305-1308.

Ohmori O, Shinkai T, Kojima H, Terao T, Suzuki T, Mita T et al (1998). Association study of a functional catechol-O-methyltransferase gene polymorphism in Japanese schizophrenics. Neurosci Lett 243: 109-112.

Palmatier MA, Kang AM, Kidd KK (1999). Global variation in the frequencies of functionally different catechol-O-methyltransferase alleles. Biol Psychiatry 46: 557-567.

Qian Q, Wang Y, Zhou R, Li J, Wang B, Glatt S et al (2003). Familybased and case-control association studies of catechol-Omethyltransferase in attention deficit hyperactivity disorder suggest genetic sexual dimorphism. Am J Med Genet 118B: 103-109.

Roy A, Agren H, Pickar D, Linnoila M, Doran AR, Cutler NR et al (1986). Reduced CSF concentrations of homovanillic acid and homovanillic acid to 5-hydroxyindoleacetic acid ratios in depressed patients: relationship to suicidal behavior and dexamethasone nonsuppression. Am J Psychiatry 143: 1539-1545.

Roy A, Rylander G, Sarchiapone M (1997). Genetics of suicides: family studies and molecular genetics. Ann NY Acad Sci 836: 135-157.

Shifman S, Bronstein M, Sternfeld M, Pisante-Shalom A, LevLehman E, Weizman A et al (2002). A highly significant association between a COMT haplotype and schizophrenia. Am J Hum Genet 71: 1296-1302.

Strous RD, Bark N, Parsia SS, Volavka J, Lachman HM (1997). Analysis of a functional catechol-O-methyltransferase gene polymorphism in schizophrenia: evidence for association with aggressive and antisocial behavior. Psychiatry Res 69: 71-77. 